\title{
Association of body temperature and antipyretic treatments with mortality of critically ill patients with and without sepsis: multi-centered prospective observational study
}

for Fever and Antipyretic in Critically ill patients Evaluation (FACE) Study Group, Byung Ho Lee ${ }^{1}$, Daisuke Inui ${ }^{2}$, Gee Young Suh ${ }^{3}$, Jae Yeol Kim ${ }^{4}$, Jae Young Kwonn ${ }^{5}$, Jisook Park ${ }^{6}$, Keiichi Tada ${ }^{7}$, Keiji Tanaka ${ }^{8}, K^{2}$ Kenichi letsugu', Kenji Uehara ${ }^{7}$, Kentaro Dote $^{10}$, Kimitaka Tajimi ${ }^{11}$, Kiyoshi Morita ${ }^{12}$, Koichi Matsuo ${ }^{13}$, Koji Hoshino ${ }^{14}$,

Koji Hosokawa ${ }^{15}$, Kook Hyun Lee ${ }^{16}$, Kyoung Min Lee ${ }^{17}$, Makoto Takatori ${ }^{7}$, Masaji Nishimura ${ }^{2}$, Masamitsu Sanui ${ }^{18}$, Masanori Ito ${ }^{9}$, Moritoki Egi ${ }^{12^{*}}$, Naofumi Honda ${ }^{14}$, Naoko Okayama ${ }^{19}$, Nobuaki Shime ${ }^{15}$, Ryosuke Tsuruta ${ }^{20}$, Satoshi Nogami ${ }^{7}$, Seok-Hwa Yoon ${ }^{21}$, Shigeki Fujitani ${ }^{22}$, Shin Ok Koh ${ }^{23}$, Shinhiro Takeda ${ }^{8}$, Shinsuke Saito ${ }^{9}$, Sung Jin Hong ${ }^{24}$, Takeshi Yamamoto ${ }^{8}$, Takeshi Yokoyama ${ }^{14}$, Takuhiro Yamaguchi ${ }^{25}$, Tomoki Nishiyama ${ }^{26}$, Toshiko Igarashi $^{11}$, Yasuyuki Kakihana ${ }^{19}$ and Younsuck Koh ${ }^{27}$

\begin{abstract}
Introduction: Fever is frequently observed in critically ill patients. An independent association of fever with increased mortality has been observed in non-neurological critically ill patients with mixed febrile etiology. The association of fever and antipyretics with mortality, however, may be different between infective and non-infective illness.

Methods: We designed a prospective observational study to investigate the independent association of fever and the use of antipyretic treatments with mortality in critically ill patients with and without sepsis. We included 1,425 consecutive adult critically ill patients (without neurological injury) requiring $>48$ hours intensive care admitted in 25 ICUs. We recorded four-hourly body temperature and all antipyretic treatments until ICU discharge or 28 days after ICU admission, whichever occurred first. For septic and non-septic patients, we separately assessed the association of maximum body temperature during ICU stay (MAX ICU) and the use of antipyretic treatments with 28day mortality.
\end{abstract}

Results: We recorded body temperature 63,441 times. Antipyretic treatment was given 4,863 times to 737 patients (51.7\%). We found that treatment with non-steroidal anti-inflammatory drugs (NSAIDs) or acetaminophen independently increased 28-day mortality for septic patients (adjusted odds ratio: NSAIDs: 2.61, $P=0.028$, acetaminophen: 2.05, $P=0.01$ ), but not for non-septic patients (adjusted odds ratio: NSAIDs: 0.22, $P=0.15$, acetaminophen: $0.58, P=0.63$ ). Application of physical cooling did not associate with mortality in either group. Relative to the reference range (MAX $X_{I C U} 36.5^{\circ} \mathrm{C}$ to $37.4^{\circ} \mathrm{C}$ ), MAX $I C \cup \geq 39.5^{\circ} \mathrm{C}$ increased risk of 28-day mortality in septic patients (adjusted odds ratio 8.14, $P=0.01$ ), but not in non-septic patients (adjusted odds ratio $0.47, P=$ $0.11)$.

Conclusions: In non-septic patients, high fever $\left(\geq 39.5^{\circ} \mathrm{C}\right)$ independently associated with mortality, without association of administration of NSAIDs or acetaminophen with mortality. In contrast, in septic patients,

\footnotetext{
* Correspondence: moriori@tg8.so-net.ne.jp

${ }^{12}$ Department of Intensive Care, Okayama University Hospital, Okayama,

Japan

Full list of author information is available at the end of the article
} 


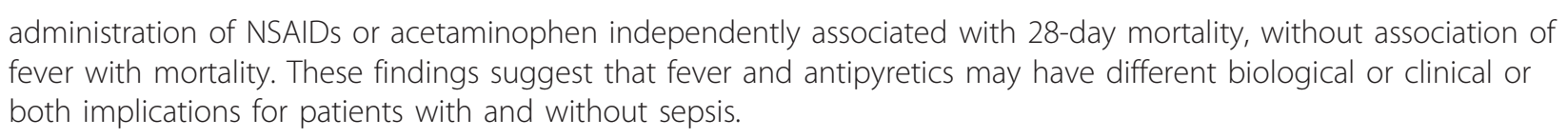
fever with mortality. These findings suggest that fever and antipyretics may have different biological or clinical or both implications for patients with and without sepsis.

Trial registration: ClinicalTrials.gov: NCT00940654

Keywords: body temperature, antipyretic, fever, critical illness, mortality

\section{Introduction}

Fever frequently occurs in critically ill patients [1]. Although fever is primarily a symptom of infection [2], it also occurs as a host's response to non-infectious inflammatory stimulus [3]. Currently, the effect of antipyretics on patient outcomes remains unclear and there are no recommendations for antipyretic treatments for non-neurological critically ill patients $[2,4]$.

Fever may have detrimental effects, especially in lifethreatening illnesses, by increasing the metabolic rate, minute ventilation and oxygen consumption, and by adversely affecting neurological outcomes [5-7]. Thus, antipyretic treatments are frequently administered in critically ill patients both with and without infectious diseases [8-10].

Fever below a fatal temperature, however, could be a host response against infectious disease resulting in reduced bacterial growth, promotion of the synthesis of antibodies and cytokines, and activation of $\mathrm{T}$ cells, neutrophils and macrophages [11-13]. Several studies have suggested that suppression of infective febrile responses with antipyretic treatments might worsen outcomes $[14,15]$.

Based on the studies mentioned above, it would be desirable to understand whether there is an independent association of fever and the use of antipyretic treatments with mortality in infective critical ill patients and whether this association is the same in non-infective critical ill patients.

Accordingly, we conducted a multicenter prospective observational study to test the hypothesis that an independent association of fever and antipyretic treatments with mortality was significantly modified by the presence of sepsis at admission to the ICU.

\section{Materials and methods Study design}

This study was a prospective observational investigation conducted in 25 hospitals: 10 in Korea and 15 in Japan. Among these 25 hospitals, 20 were academic tertiary care hospitals and 5 were community hospitals. Participating hospitals range in size from 248 to 2,860 beds (median of 736) and included a total of 1,002 ICU beds (median of 20 beds per ICU). Data collection and data analysis for this study were approved by each of the local institutional ethics committees, and each waived the requirement for informed consent.

\section{Patients}

At each participating site, all adult patients who required intensive care for more than 48 hours from 1 September 2009 to 30 November 2009 were candidates for enrollment in the study; we excluded patients with post-cardiac arrest, post craniotomy, traumatic brain injury, central nervous system infection, subarachnoid hemorrhage, intracerebral hemorrhage or stroke at their ICU admission.

We separated our cohorts into patients with and without sepsis for the first 24 hours of ICU admission. Sepsis was defined as the presence of microbiologically proven, clinically affirmed or suspected infection along with the presence of systemic inflammatory response syndrome $[16,17]$.

\section{Data collection \\ Demographic data}

Age, sex, reason for admission, use of mechanical ventilation and Acute Physiology and Chronic Health Evaluation (APACHE) II score [18] were recorded. Coding for major admission diagnosis was categorized as cardiac or vascular disease, thoracic or respiratory disease, renal or metabolic disease, gastrointestinal tract disease, and other.

\section{Body temperature}

We recorded four-hourly body temperature until either time of ICU discharge or 28 days after ICU admission, whichever occurred first. Measuring methods included use of pulmonary artery and bladder catheter thermistors, tympanic membrane and axillary thermometers. When body temperature was simultaneously measured using more than one method, we recorded the value measured by the method most preferred by the American College of Critical Care Medicine and the Infectious Diseases Society of America [2].

\section{Information for antipyretic treatments}

While no standardized protocols for the prevention or treatment of fever were applied across the participating ICUs, we recorded all the antipyretic treatments during ICU stay; including non-steroidal anti-inflammatory drugs (NSAIDs), acetaminophen and physical cooling. 
Body temperature at commencement of antipyretic treatment was also recorded. Information for NSAIDs and acetaminophen was recorded only when these were administered for fever management, not for pain control. Physical cooling methods included external air and water blanket techniques, and internal cold gastric lavage or cold fluid infusion.

\section{Outcome}

The primary outcome of interest was mortality up to 28 days after ICU admission, and the association of this with peak body temperature during ICU stay and administered antipyretic treatments. Patients who were discharged alive from the hospital before Day 28 were defined as survived.

\section{Statistical analysis}

Categorical variables were summarized using proportions and compared between groups using the chisquare test and continuous variables were summarized using mean (SD) or median (interquartile range; IQR) and compared between groups using Student's $t$-test or the Wilcoxon rank-sum test as appropriate.

To determine the severity of fever, we considered maximum body temperature $\left(\mathrm{MAX}_{\mathrm{ICU}}\right)$, the highest body temperature recorded during ICU stay. As the relationship between body temperature and mortality may not be linear, we treated body temperature as a categorical variable. MAX $\mathrm{ICU}_{\mathrm{C}}$ was analyzed in five range categories: (A) $<36.5^{\circ} \mathrm{C}$, (B) $36.5^{\circ} \mathrm{C}$ to $37.4^{\circ} \mathrm{C}$, (C) $37.5^{\circ} \mathrm{C}$ to $38.4^{\circ} \mathrm{C}$, (D) $38.5^{\circ} \mathrm{C}$ to $39.4^{\circ} \mathrm{C}$ and $(\mathrm{E}) \geq 39.5^{\circ} \mathrm{C}$. Odds ratios are reported relative to a reference body temperature, defined here as category (B) $\left(36.5^{\circ} \mathrm{C}\right.$ to $\left.37.4^{\circ} \mathrm{C}\right)$. Additionally, we performed survival log-rank test to compare each range categories.

We performed multivariate logistic regression analysis, treating as independent variables, site, age, use of mechanical ventilation, APACHE-II score with the body temperature component removed [18], category of ICU admission, whether surgical or medical admission, subgroup of $\mathrm{MAX}_{\mathrm{ICU}}$, application of antipyretic treatment; the dependent variable was death within 28 days of admission. Model calibration was determined using the Hosmer-Lemeshow test for goodness of fit. Results from the multivariate models are reported using odds ratios with $95 \%$ confidence intervals.

For sensitivity analysis, we further developed another multivariate model among patients with lowest body temperature during ICU stay $>35^{\circ} \mathrm{C}$. We defined this threshold $\left(>35^{\circ} \mathrm{C}\right)$ as a recent large epidemiological study defined $35^{\circ} \mathrm{C}$ as the threshold of moderate to severe hypothermia [19].

We assumed $50 \%$ of the study patients had sepsis, a quarter of them were prescribed antipyretic therapy and the mortality of ICU patients was $12 \%$. Assuming an $8 \%$ change in ICU mortality with antipyretic both in septic and non-septic patients, a power of 0.80 , and an $\alpha$ level of 0.05 , we required 1,400 participants. As we expected to include approximately 500 participants per month, we planned to conduct the current study for three months.

$P$-values of less than 0.05 were considered statistically significant. All analyses were performed using commercially available statistical software (SPSS 19.0, SPSS Inc, Chicago, IL, USA). Data are reported in accordance with the guidelines laid out in Strengthening the Reporting of Observational Studies in Epidemiology (STROBE) [20].

\section{Results}

We studied 1,429 consecutive patients. We excluded four patients for whom data were incomplete $(4 / 1,429$, $0.3 \%$ ), leaving a total of 1,425 patients with 63,441 body temperature measurements eligible for inclusion in the study. Seventy-two percent of body temperature was measured by axillary thermometers, $16 \%$ by bladder catheter thermistors, $9 \%$ by tympanic membrane thermometers and $3 \%$ by pulmonary artery catheter thermistors. The median APACHE II score was 17, and 28-day mortality was $12.0 \%$. The median length of stay in ICU was 7 days and in hospital 26 days. Among the 1,425 patients, 606 patients met the criteria for sepsis during the first $24 \mathrm{~h}$. The remaining 819 patients were without sepsis (Figure 1).

Table 1 provides clinical characteristics, MAX $_{\mathrm{ICU}}$ and antipyretic treatments for septic and non-septic patients and for the total cohort. Septic patients tended to be more severely ill, older and were less likely to be postoperative patients or to have required mechanical ventilation during ICU stay. The 28-day mortality in septic patients was significantly higher than in non-septic patients.

Septic patients exhibited significantly higher MAX $\mathrm{ICU}_{\mathrm{I}}$ than non-septic patients $\left(38.3^{\circ} \mathrm{C}\right.$ vs. $\left.37.8^{\circ} \mathrm{C}, P<0.001\right)$. MAX $_{\text {ICU }}$ in septic patients was more frequently in the higher range $\left(\geq 38.5^{\circ} \mathrm{C}\right)$ (Table 1$)$. This difference was present for the first seven days of ICU stay (Figure 2).

Table 2 shows 28 -day mortality and odds ratio for each range of MAX $\mathrm{ICU}_{\mathrm{ICU}}$ relative to the reference range of $36.5^{\circ} \mathrm{C}$ to $37.4^{\circ} \mathrm{C}$ in septic and non-septic patients, respectively. Mortality did not relate to MAX $\mathrm{ICU}_{\text {in sep- }}$ tic patients. By contrast, for non-septic patients, 28-day mortality increased according to $\mathrm{MAX}_{\mathrm{ICU}}$, and was significantly greater when $\mathrm{MAX}_{\mathrm{ICU}}$ was $\geq 38.5^{\circ} \mathrm{C}$ (odds ratio; $5.13(P<0.007)$ and $13.4(P<0.001), 38.5^{\circ} \mathrm{C}$ to $39.4^{\circ} \mathrm{C}$ and $\geq 39.5^{\circ} \mathrm{C}$, respectively). There was no significant difference in 28-day mortality between patients with single and multiple episodes of $\operatorname{MAX}_{\mathrm{ICU}} \geq 39.5^{\circ} \mathrm{C}$. Mortality for septic patients with $\mathrm{MAX}_{\mathrm{ICU}}<36.5^{\circ} \mathrm{C}$ was 


\section{9 critically ill patients}

without any neurological injury and derangement

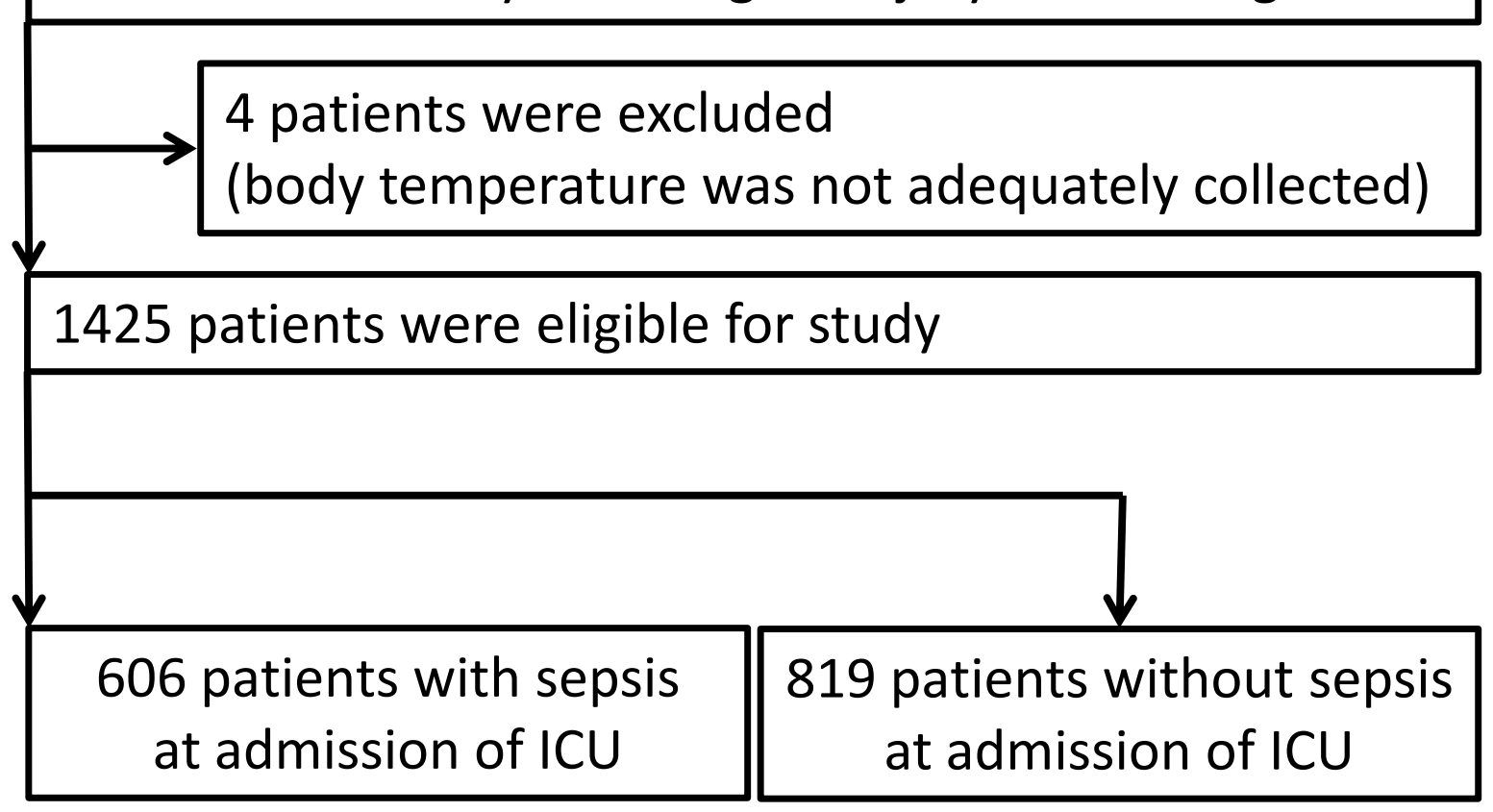

Figure 1 Flow chart showing current study. ICU, intensive care units.

as high as $50 \%$, but no significant difference was detected owing to the small number of patients in this category $(n=4)$ (odds 3.08, $P=0.57$ ).

Figure 3 shows Kaplan-Meier estimates for the probability, which at 28 days was greater in non-septic patients with $\mathrm{MAX}_{\mathrm{ICU}} \geq 38.5^{\circ} \mathrm{C}$ than those with temperatures of $36.5^{\circ} \mathrm{C}$ to $37.4^{\circ} \mathrm{C}$. In septic patients, there were no significant differences of provability of survival in each category compared with patients of MAX $\mathrm{ICU}$ with $36.5^{\circ} \mathrm{C}$ to $37.4^{\circ} \mathrm{C}$.

Antipyretic treatment was applied 4,863 times to 737 patients (51.7\%). NSAIDs were administered 429 times to 130 patients $(9.1 \%)$, acetaminophen was administered 571 times to 148 patients (10.4\%) and physical cooling was applied 3,863 times to 671 patients (47.1\%). Delta body temperature from application of antipyretic to next temperature monitoring was $-0.3^{\circ} \mathrm{C}$ (IQR; -0.7, 0.0) and $-0.4^{\circ} \mathrm{C}$ (IQR; -0.9, -0.2), for NSAIDs and acetaminophen respectively, which is significantly greater than $-0.1^{\circ} \mathrm{C}$ for physical cooling $(P<0.001)$ (Table 1$)$.

Figure 3 shows the proportion of patients who received pharmacological antipyretic treatments (NSAIDs, acetaminophen or both) in each subgroup. For the subgroup with $\mathrm{MAX}_{\mathrm{ICU}}$ of $37.5^{\circ} \mathrm{C}$ to $38.4^{\circ} \mathrm{C}$, the proportion of patients who received pharmacological antipyretic treatments was significantly higher than in non-septic patients $(P=0.007)$. For the rest of the subgroups, it was not significantly different between patients with and without sepsis $\left(38.5^{\circ} \mathrm{C}\right.$ to $39.4^{\circ} \mathrm{C}, P=$ 0.62 ; $\left.\geq 39.5^{\circ} \mathrm{C}, P=0.25\right)$. Acetaminophen was used more frequently for septic patients, and NSAIDs for non-septic patients in each range of $\mathrm{MAX}_{\mathrm{ICU}}(P<$ 0.001 ) (Figure 3). Figure 4 shows the proportion of septic and non-septic patients who received physical cooling. Physical cooling was applied frequently in septic patients, when $\mathrm{MAX}_{\mathrm{ICU}}$ was $\leq 39.4^{\circ} \mathrm{C}$ (Figure 5).

Table 3 shows univariate comparisons of patient demographic data and antipyretic treatments. In septic patients, the use of NSAIDs and acetaminophen was significantly associated with increased mortality (odds ratio: NSAIDs 2.32, $P=0.02$; acetaminophen $2.30, P=0.002$ ) (Table 3 ). By contrast, for non-septic patients, the pharmacological antipyretic treatments were not associated with mortality (odds ratio: NSAIDs $0.20, P=0.08$; acetaminophen $0.69, P$ $=0.72$ ). Physical cooling was associated with mortality in neither septic nor non-septic patients (odds ratio: with sepsis $1.00, P=0.99$; without sepsis $1.14, P=0.74$ ).

\section{Multivariate analysis}

As shown in Table 3, the presence of confounders, such as severity of illness, age, reason for ICU admission and mechanical ventilation requirement, necessitated 
Table 1 Comparison of baseline characteristics of patients with and without sepsis

\begin{tabular}{|c|c|c|c|c|}
\hline & $\begin{array}{c}\text { Patients } \\
\text { with sepsis } \\
(N=606)\end{array}$ & $\begin{array}{c}\text { Patients } \\
\text { without sepsis } \\
(N=819)\end{array}$ & $P$-value & $\begin{array}{l}\text { Total cohort } \\
(N=1425)\end{array}$ \\
\hline 28-day mortality n (\%) & $135(22.3 \%)$ & $36(4.4 \%)$ & $<0.001$ & $171(12.0 \%)$ \\
\hline Gender (male) n (\%) & $385(63.5 \%)$ & $508(62 \%)$ & 0.56 & $893(62.7 \%)$ \\
\hline Age (y.o, IQR) & $67(55,75)$ & $65(54,73)$ & 0.015 & $66(54,74)$ \\
\hline APACHE II score (IQR) & $21(16,25)$ & $14(10,18)$ & $<0.001$ & $17(12,22)$ \\
\hline Mechanical ventilation requirement $\mathrm{n}(\%)$ & $429(70.8 \%)$ & $528(64.5 \%)$ & 0.01 & $957(67.2 \%)$ \\
\hline Postoperative admission n (\%) & $68(11.2 \%)$ & $538(65.7 \%)$ & $<0.001$ & $602(42.2 \%)$ \\
\hline \multicolumn{5}{|l|}{ Reasons for admission n (\%) } \\
\hline Cardiac or vascular disease & $109(18.0 \%)$ & $435(53.1 \%)$ & $<0.001$ & $544(38.2 \%)$ \\
\hline Thoracic or respiratory disease & $343(56.6 \%)$ & $205(25.0 \%)$ & $<0.001$ & $548(38.4 \%)$ \\
\hline Renal or metabolic disease & $61(10.0 \%)$ & $54(6.6 \%)$ & 0.018 & $115(8.1 \%)$ \\
\hline Gastrointestinal tract disease & $68(11.2 \%)$ & $108(13.1 \%)$ & 0.26 & $176(12.4 \%)$ \\
\hline Other & $25(4.1 \%)$ & $17(2.1 \%)$ & 0.024 & $42(2.9 \%)$ \\
\hline Length of stay in ICU & $8(5,14)$ & $5(4,7)$ & $<0.001$ & $6(4,10)$ \\
\hline $\operatorname{MAX}_{\mathrm{ICU}}\left({ }^{\circ} \mathrm{C}, \mathrm{IQR}\right)$ & $38.3(37.7,39.0)$ & $37.8(37.4,38.3)$ & $<0.001$ & $38.0(37.5,38.6)$ \\
\hline$<36.5^{\circ} \mathrm{C}$ & $4(0.7 \%)$ & $2(0.2 \%)$ & 0.43 & $6(0.4 \%)$ \\
\hline $36.5^{\circ} \mathrm{C}$ to $37.4^{\circ} \mathrm{C}$ & $98(16.2 \%)$ & $240(29.3 \%)$ & $<0.001$ & $338(23.7 \%)$ \\
\hline $37.5^{\circ} \mathrm{C}$ to $38.4^{\circ} \mathrm{C}$ & $237(39.1 \%)$ & $425(52.0 \%)$ & $<0.001$ & $662(46.5 \%)$ \\
\hline $38.5^{\circ} \mathrm{C}$ to $39.4^{\circ} \mathrm{C}$ & $185(30.5 \%)$ & $125(15.3 \%)$ & $<0.001$ & $310(21.8 \%)$ \\
\hline$\geq 39.5^{\circ} \mathrm{C}$ & $82(13.5 \%)$ & 27 (3.3\%) & $<0.001$ & $109(7.6 \%)$ \\
\hline \multicolumn{5}{|l|}{ NSAIDs } \\
\hline Number of patients administered n (\%) & $31(5.1 \%)$ & 99 (12.1\%) & $<0.001$ & $130(9.1 \%)$ \\
\hline Delta body temperature ${ }^{*}\left({ }^{\circ} \mathrm{C}, \mathrm{IQR}\right)$ & $-0.3(-0.8,0.0)$ & $-0.4(-0.7,0.0)$ & 0.57 & $-0.3(-0.7,0.0)$ \\
\hline \multicolumn{5}{|l|}{ Acetaminophen } \\
\hline Number of patients administered n (\%) & $116(19.1 \%)$ & 32 (3.9\%) & $<0.001$ & $148(10.4 \%)$ \\
\hline Delta body temperature* $\left({ }^{\circ} \mathrm{C}, \mathrm{IQR}\right)$ & $-0.4(-0.8,-0.2)$ & $-0.3(-0.7,0.0)$ & 0.14 & $-0.4(-0.9,-0.2)$ \\
\hline \multicolumn{5}{|l|}{ Physical cooling } \\
\hline Number of patients administered n (\%) & $307(50.7 \%)$ & $364(44.4 \%)$ & 0.02 & $671(47.1 \%)$ \\
\hline Delta body temperature ${ }^{*}\left({ }^{\circ} \mathrm{C}, \mathrm{IQR}\right)$ & $-0.2(-0.5,0.0)$ & $-0.1(-0.3,0.0)$ & $<0.001$ & $-0.1(-0.3,0.0)$ \\
\hline
\end{tabular}

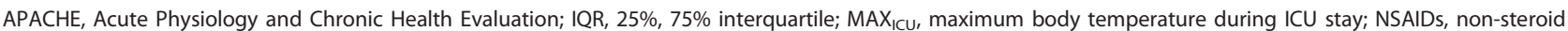
anti-inflammatory drugs

*, Delta body temperature from application of antipyretic to next temperature monitoring

multivariate analysis adjusting for relevant predictors of 28-day mortality.

In septic patients relative to the reference range $\left(36.5^{\circ}\right.$ $\mathrm{C}$ to $37.4^{\circ} \mathrm{C}$ ), $\mathrm{MAX}_{\mathrm{ICU}} 37.5^{\circ} \mathrm{C}$ to $38.4^{\circ} \mathrm{C}$ was associated with decreased mortality (adjusted odds ratio 0.45, $P=$ 0.014 ) and $\mathrm{MAX}_{\mathrm{ICU}} \geq 38.5^{\circ} \mathrm{C}$ was not (adjusted odds ratio $38.5^{\circ} \mathrm{C}$ to $39.4^{\circ} \mathrm{C} ; 0.52, P=0.09, \geq 39.5^{\circ} \mathrm{C} ; 0.47, P=$ $0.11)$. In non-septic patients, adjusted risk of death was increased as $\mathrm{MAX}_{\mathrm{ICU}}$ increased, and $\mathrm{MAX}_{\mathrm{ICU}} \geq 39.5^{\circ} \mathrm{C}$ was associated with mortality (adjusted odds ratio 8.14, $P=0.01$ ) (Table 4).

In septic patients, administration of NSAIDs or acetaminophen was independently associated with mortality (adjusted odds ratio: NSAIDs 2.61, $P=0.028$; acetaminophen $2.05, P=0.01$ ). In non-septic patients, the pharmacological antipyretic treatments were not associated with mortality (adjusted odds ratio: NSAIDs $0.22, P=0.15$; acetaminophen $0.58, P=0.63$ ) (Table 4 ). The model was a good fit for data from both groups (Hosmer-Lemeshow: with sepsis, $P=0.21$, without sepsis, $P=0.89$ ).

To exclude the possible effects of hypothermia, we further performed multivariate logistic analysis excluding data from 106 patients with low body temperature $\left(\leq 35^{\circ} \mathrm{C}\right)$ during ICU stay (Table 5). Even in this model, administration of NSAIDs and acetaminophen in septic patients was independently associated with mortality (adjusted odds ratio: NSAIDs 2.48, $P=0.04$; acetaminophen 1.95, $P=0.03$ ). Meanwhile, for non-septic patients, MAX $_{\mathrm{ICU}} \geq 38.5^{\circ} \mathrm{C}$ was associated with mortality (adjusted odds ratio $38.5^{\circ} \mathrm{C}$ to $39.4^{\circ} \mathrm{C} ; 7.49, P=0.02$, $\geq$ $\left.39.5^{\circ} \mathrm{C} ; 11.7, P=0.02\right)$.

\section{Discussion}

\section{Key results}

We performed a study to explore the relationship of fever and antipyretic treatments with 28-day mortality 


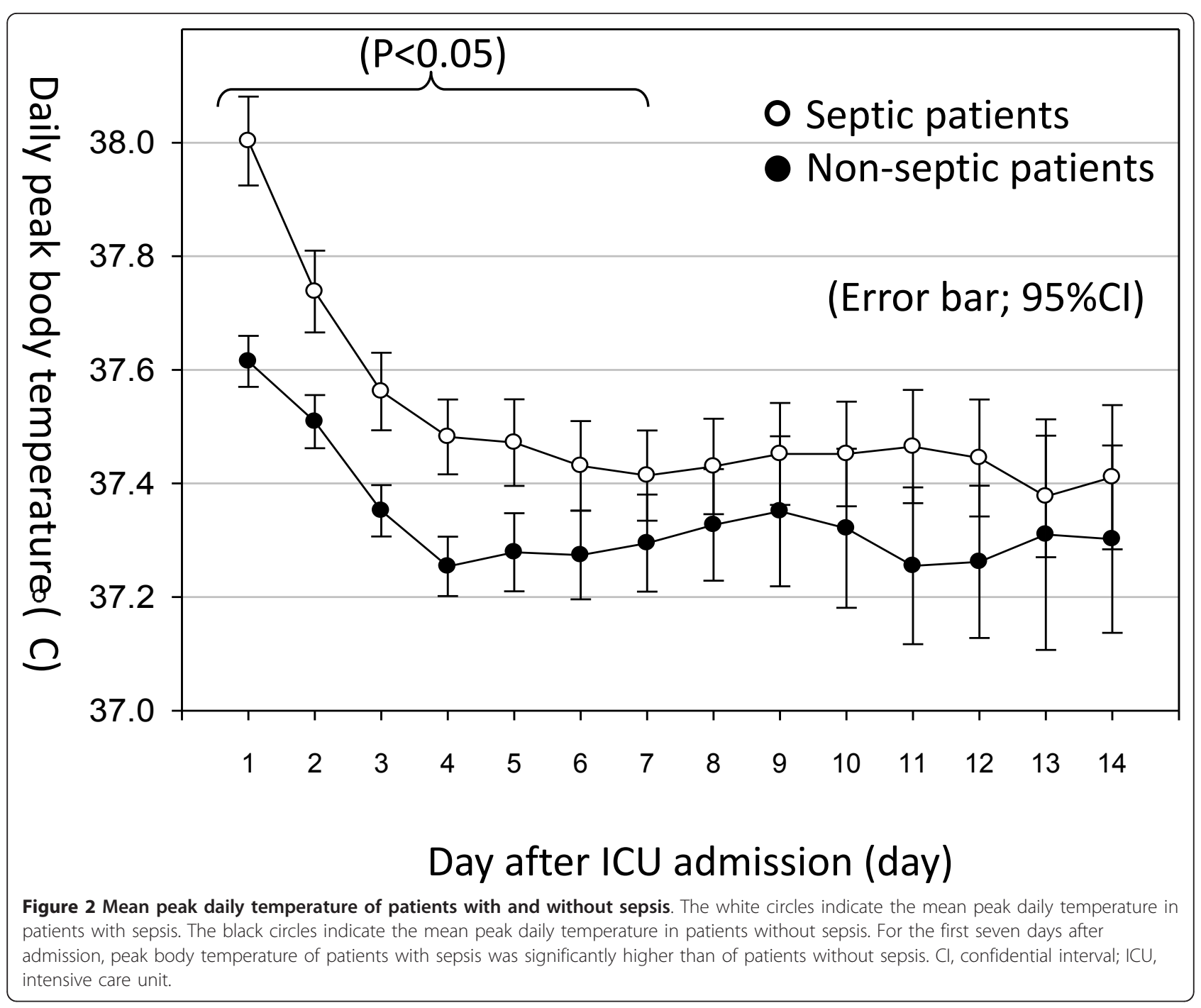

Table 2 Maximum body temperature during ICU stay and 28-day mortality of patients with and without sepsis.

\begin{tabular}{|c|c|c|c|c|}
\hline \multirow[t]{2}{*}{$M_{A X} X_{I C U}$} & \multicolumn{2}{|c|}{$\begin{array}{l}\text { Patients with sepsis } \\
\qquad(N=606)\end{array}$} & \multicolumn{2}{|c|}{$\begin{array}{l}\text { Patients without sepsis } \\
\qquad(N=819)\end{array}$} \\
\hline & $\begin{array}{l}\text { 28-day } \\
\text { mortality }\end{array}$ & $\begin{array}{c}\text { Unadjusted } \\
\text { odds ratio }(95 \% \mathrm{Cl})\end{array}$ & $\begin{array}{l}\text { 28-day } \\
\text { mortality }\end{array}$ & $\begin{array}{c}\text { Unadjusted } \\
\text { odds ratio }(95 \% \mathrm{Cl}) \\
\end{array}$ \\
\hline$<36.5^{\circ} \mathrm{C}$ & $\begin{array}{c}2 / 4 \\
(50.0 \%)\end{array}$ & $\begin{array}{c}3.08(0.41,23.1) \\
\quad(P=0.57)\end{array}$ & $\begin{array}{l}0 / 2 \\
(0 \%)\end{array}$ & n.a. \\
\hline $36.5^{\circ} \mathrm{C}$ to $37.4^{\circ} \mathrm{C}$ & $\begin{array}{l}24 / 98 \\
(24.5 \%)\end{array}$ & $\begin{array}{c}1 \\
\text { (reference) }\end{array}$ & $\begin{array}{l}4 / 240 \\
(1.7 \%)\end{array}$ & $\begin{array}{c}1 \\
\text { (reference) }\end{array}$ \\
\hline $37.5^{\circ} \mathrm{C}$ to $38.4^{\circ} \mathrm{C}$ & $\begin{array}{l}40 / 237 \\
(16.9 \%)\end{array}$ & $\begin{array}{c}0.63(0.35,1.11) \\
(P=0.14)\end{array}$ & $\begin{array}{l}17 / 425 \\
(4.0 \%)\end{array}$ & $\begin{array}{l}2.46(0.82,7.40) \\
\quad(P=0.44)\end{array}$ \\
\hline $38.5^{\circ} \mathrm{C}$ to $39.4^{\circ} \mathrm{C}$ & $\begin{array}{l}44 / 185 \\
(23.8 \%)\end{array}$ & $\begin{array}{c}0.96(0.54,1.70) \\
(P=0.99)\end{array}$ & $\begin{array}{l}10 / 125 \\
(8.0 \%)\end{array}$ & $\begin{array}{c}5.13(1.58,16.7) \\
\quad(P=0.007)\end{array}$ \\
\hline$\geq 39.5^{\circ} \mathrm{C}$ & $\begin{array}{l}25 / 82 \\
(30.5 \%)\end{array}$ & $\begin{array}{c}1.35(0.70,2.61) \\
(P=0.46)\end{array}$ & $\begin{array}{c}5 / 27 \\
(18.5 \%)\end{array}$ & $\begin{array}{c}13.4(3.35,53.6) \\
\quad(P<0.001)\end{array}$ \\
\hline
\end{tabular}

Unadjusted odds ratio was reported relative to a reference body temperature defined as category $36.5^{\circ} \mathrm{C}$ to $37.4^{\circ} \mathrm{C}$.

$\mathrm{Cl}$, confidential interval; ICU, intensive care unit; $\mathrm{MAX}_{\mathrm{ICU}}$, maximum body temperature during an ICU stay; n.a., not applicable (no patients in this category) 


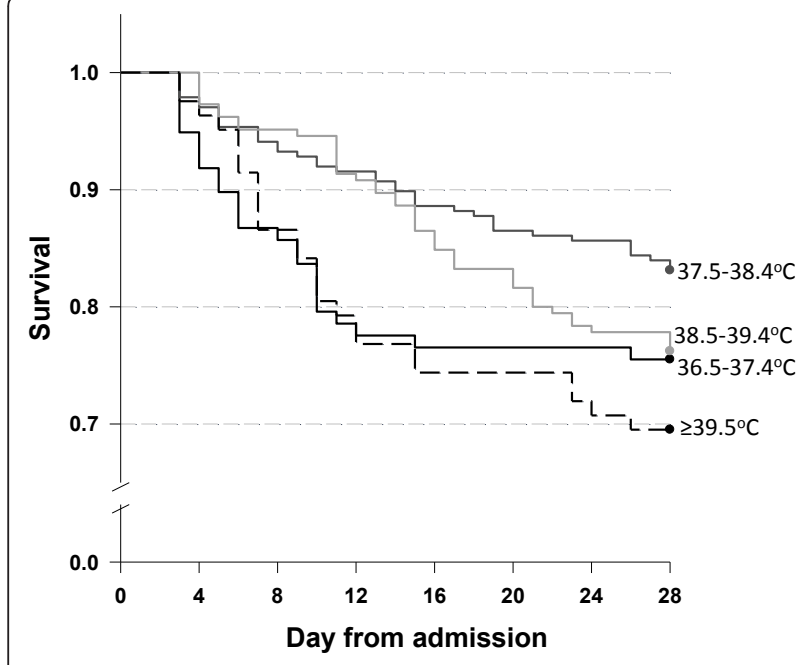

Septic patients

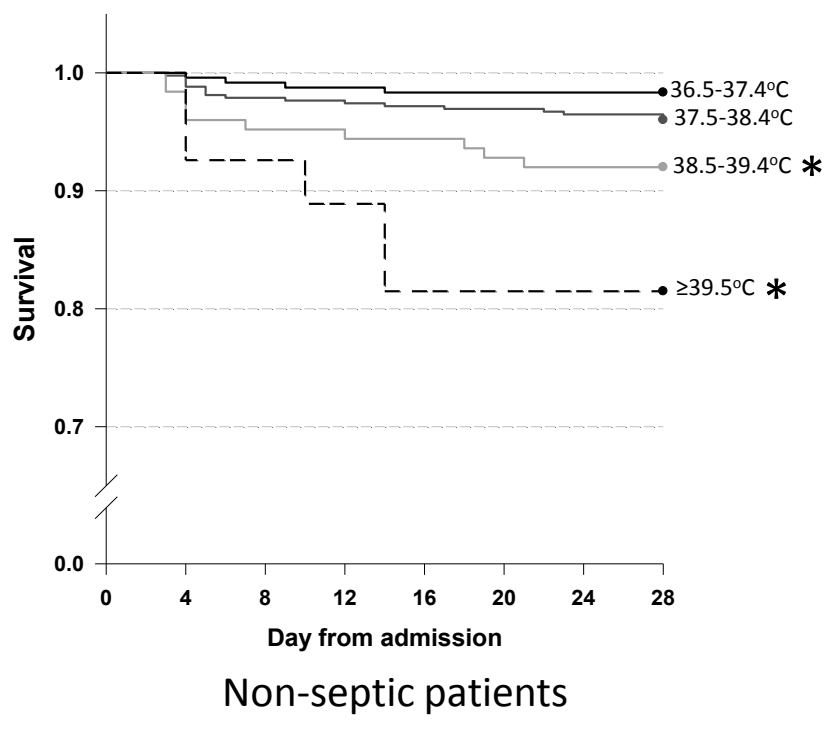

Figure 3 Maximum body temperature during ICU stay and survival of patients with and without sepsis. This figure shows Kaplan-Meier estimates for the probability of survival, which at 28 days was greater in non-septic patients with $\mathrm{MAX}_{1 \mathrm{CU}} 38.5^{\circ} \mathrm{C}$ to $39.4^{\circ} \mathrm{C}$ and $\geq 39.5^{\circ} \mathrm{C}$ than those with $36.5^{\circ} \mathrm{C}$ to $37.4^{\circ} \mathrm{C}$. In septic patients, there were no significant differences of provability of survival in each category compared with patients of MAX $\mathrm{ICU}$ with $36.5^{\circ} \mathrm{C}$ to $37.4^{\circ} \mathrm{C}$. ${ }^{*}$, significantly different probability of survival at 28 days after ICU admission than patients with $36.5^{\circ} \mathrm{C}$ to $37.4^{\circ} \mathrm{C}$.

in critically ill patients and to quantify the difference of its association between patients with and without sepsis. We found that in septic patients, compared with the $36.5^{\circ} \mathrm{C}$ to $37.4^{\circ} \mathrm{C}$ subgroup, $\mathrm{MAX}_{\mathrm{ICU}} 37.5^{\circ} \mathrm{C}$ to $38.4^{\circ} \mathrm{C}$ was associated with decreased mortality and $\mathrm{MAX}_{\mathrm{ICU}} \geq$ $38.5^{\circ} \mathrm{C}$ was not independently associated with mortality. By contrast, in non-septic patients, high fever $\left(\geq 39.5^{\circ} \mathrm{C}\right)$ was independently associated with mortality. We also found significant interactions between mortality and treatment with NSAIDs or acetaminophen only in septic patients.

\section{Limitations of this study}

Our study had several limitations. First, because it was designed as an observational study without standardized protocols for antipyretic treatments, the findings can only show association and not causality. Thus, our results can only be viewed as useful for generating hypotheses.

The methods of body temperature monitoring were not standardized. Furthermore, the majority of the body temperatures was measured by axillary thermometers, although core temperature is less influenced by external factors and more accurately reflects temperature of the vital organs [21]. Additionally, it is possible that the sickest patients were more likely to have had invasive measurements of core temperature, resulting in relatively higher values. The proportion of methods of body temperature monitoring, however, used in septic patients was not significantly different from non-septic patients. Thus, any bias-related body temperature monitoring would similarly influence both cohorts. Nonetheless, our finding may be accentuated due to changes in circulation occurring during the progression of sepsis environmental temperature [22]. In this regard, our finding should be confirmed or refuted by further studies using core body temperature monitoring.

Although the proportion of patients treated with pharmacological antipyretic treatments were similar in both septic and non-septic patients, NSAIDs were more frequently administered to non-septic patients, while acetaminophen was used more frequently for septic patients. Additionally, acetaminophen was less frequently administered in the present study than in other studies. Young et al. reported that acetaminophen was administered to $58 \%$ to $70 \%$ of septic patients [10], while only to about $20 \%$ in our patients. Physical cooling was applied more frequently in our population than reported elsewhere [10]. These facts may influence their association with mortality. Thus, we duly note that our findings may not be applicable to other settings where antipyretic procedures are different. Additionally, we studied in only two countries and our findings may not be generalizable to other countries, especially those with different medical systems.

We used delta body temperature after antipyretic treatments to compare the strength of each antipyretic effect. We should note that this index did not reflect the absolute reduction of body temperature after antipyretic procedures, as the timing of temperature measurement 


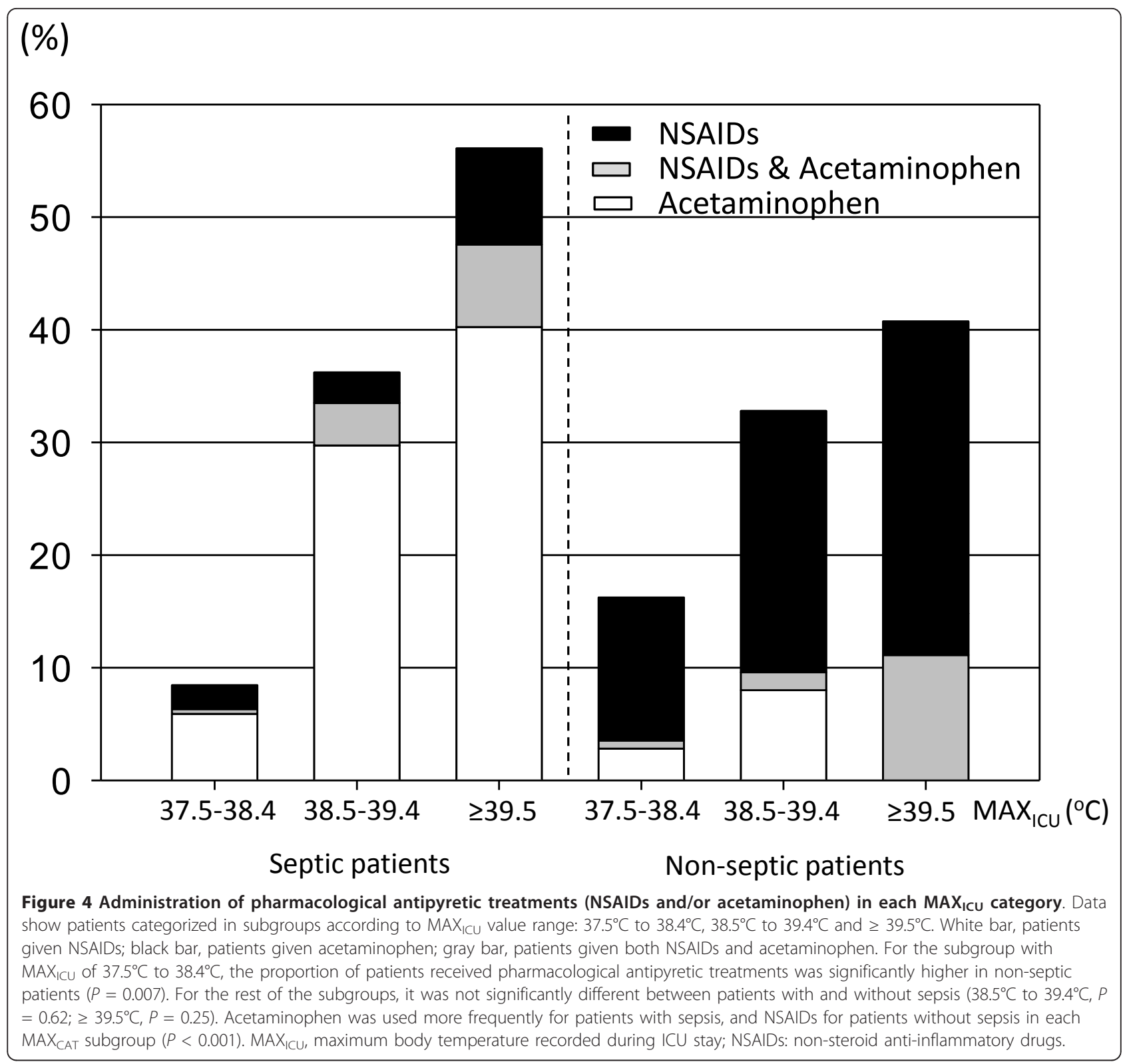

after antipyretics was not standardized and there might not be a linear relationship between individual antipyretic treatment and the next body temperature.

Finally, we excluded critically ill patients with neurological injury. It is widely accepted that fever adversely affects the outcome of critically ill patients with neurological injury $[23,24]$ and should be treated [6,7]. By contrast, there is no clear recommendation for antipyretic treatments for nonneurological critically ill patients $[2,4,25]$. Thus, we chose to exclude patients with neurological injury.

\section{Interpretation}

Although we reported associations and cannot assume causality, our finding was consistent with previous studies [26,27], suggesting that fever could be a host response that protects against infectious diseases [11-13] and use of antipyretic treatments to suppress the febrile response to infection might worsen outcomes $[14,15]$.

The association of fever with mortality varied according to the level of fever and it was independently associated with mortality only in subgroup $\geq 39.5^{\circ} \mathrm{C}$ of patients without sepsis. We assume that high fever seen in patients without sepsis was likely caused by infection subsequent to ICU admission and this may account for the higher mortality. We did find, however, that the association of MAX $\mathrm{ICU}$ and mortality were similar in patients with no sign of infection during ICU stay (Additional file 1). 


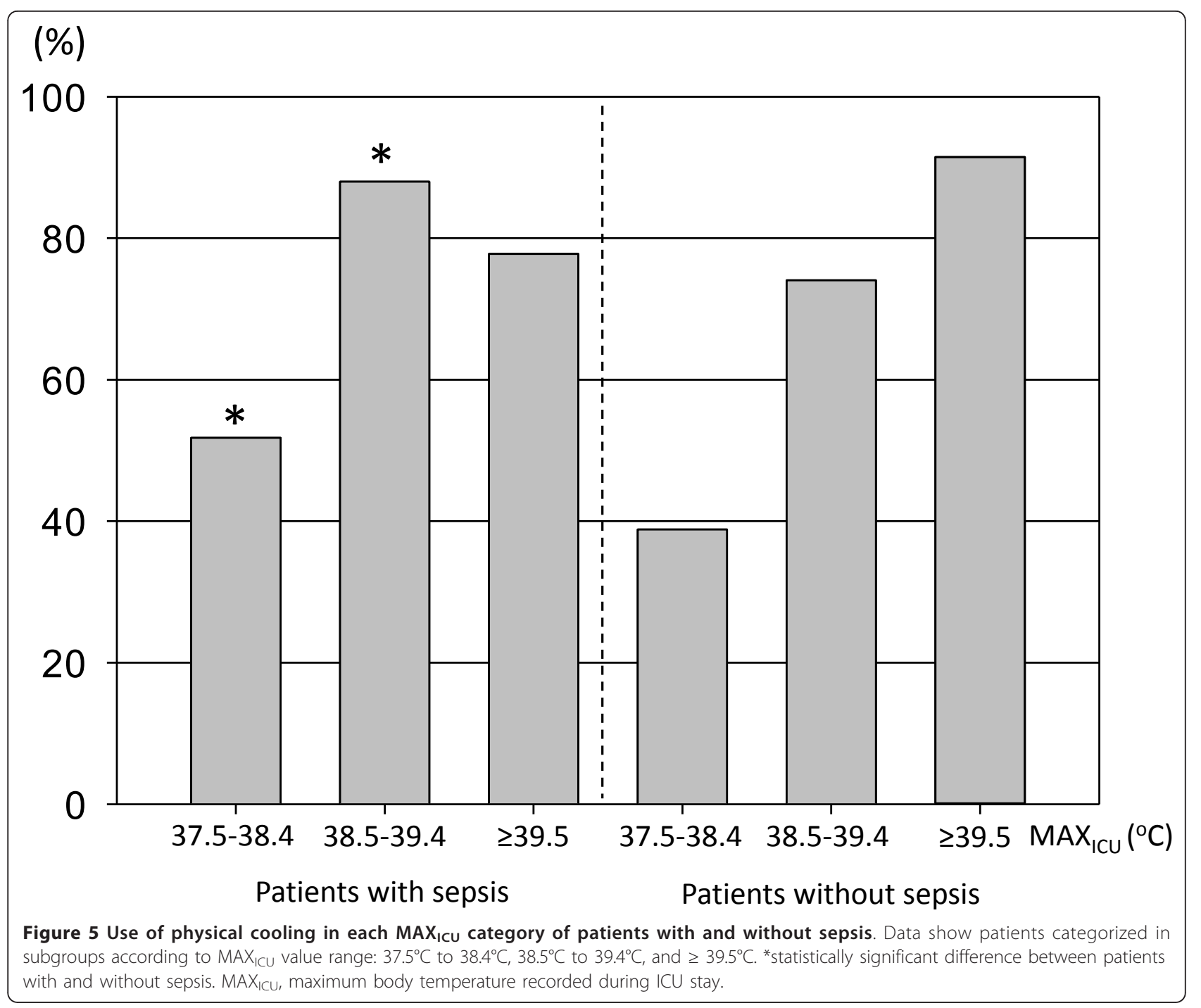

A large epidemiological study has revealed that the presence of fever $\left(\geq 38.3^{\circ} \mathrm{C}\right)$ is not associated with increased ICU mortality ( $13 \%$ vs. $12 \%$ : $P=0.08)$, but that high fever $\left(\geq 39.5^{\circ} \mathrm{C}\right)$ was associated with significantly increased mortality $(20.3 \%$ vs. $12 \%, P<0.001)$ [1]. High fever can result in cardiac arrhythmias, tachycardia, increased oxygen demand, convulsions and brain damage [5-7]. Patients with non-infective febrile responses may experience these deleterious effects without the potential benefit of fever-related protection against viruses or bacteria or both.

We found that the association with mortality of the administration of NSAIDs or acetaminophen or both was significantly different for non-septic patients than for septic patients. There are at least four possible explanations for our findings related to septic patients. First, the infective febrile response may be effective and lowering body temperature with antipyretics might be undesirable for septic patients. Fever is thought to inhibit the activity of viruses and bacteria [11-13] and antipyretic treatments shown to worsen outcomes in various animal and human studies $[14,15]$. The apparent antipyretic effects of NSAIDs and acetaminophen compared with physical cooling seen in our study lends weight to this hypothesis.

Second, in septic patients, administration of NSAIDs and acetaminophen may be toxic, as they might be associated with hypotension and renal dysfunction $[28,29]$. We could not assess this hypothesis in the current study.

Third, mortality is higher for septic patients who fail to develop a fever. We found the unadjusted mortality was as high as $66 \%$ in patients with $\mathrm{MAX}_{\mathrm{ICU}}<36.5^{\circ} \mathrm{C}$. This finding may also support the argument that fever is naturally protective. For sensitive analysis to avoid the bias of hypothermia (defined as lowest body temperature 
Table 3 Comparison of baseline characteristics and antipyretic treatments of survivors and non-survivors

\begin{tabular}{|c|c|c|c|c|c|c|}
\hline & \multicolumn{3}{|c|}{ Patients with sepsis } & \multicolumn{3}{|c|}{ Patients without sepsis } \\
\hline & $\begin{array}{l}\text { Survivors } \\
(N=471)\end{array}$ & $\begin{array}{l}\text { Non-survivors } \\
(N=135)\end{array}$ & $P$-value & $\begin{array}{l}\text { Survivors } \\
(N=783)\end{array}$ & $\begin{array}{c}\text { Non-survivors } \\
(N=36)\end{array}$ & $P$-value \\
\hline Gender (male) n (\%) & $291(61.8 \%)$ & $94(69.6 \%)$ & 0.10 & $485(61.9 \%)$ & $23(63.9 \%)$ & 0.81 \\
\hline Age (y.o., IQR) & $67(54,75)$ & $69(58,78)$ & 0.08 & $64(54,73)$ & $74.5(59,81.5)$ & 0.003 \\
\hline APACHE (IQR) & $20(16,24)$ & $24(21,28)$ & $<0.001$ & $13(10,18)$ & $24(19.5,28)$ & $<0.001$ \\
\hline Postoperative admission n (\%) & $59(12.5 \%)$ & $9(6.7 \%)$ & 0.057 & $523(66.8 \%)$ & $11(30.6 \%)$ & $<0.001$ \\
\hline Mechanical ventilation requirement $\mathrm{n}(\%)$ & $317(67.3 \%)$ & $112(83.0 \%)$ & $<0.001$ & $498(63.6 \%)$ & $30(83.3 \%)$ & 0.016 \\
\hline \multicolumn{7}{|l|}{ Reasons for admission n (\%) } \\
\hline Cardiac or vascular diseases & $93(19.7 \%)$ & $16(11.9 \%)$ & 0.04 & $422(53.9 \%)$ & $13(36.1 \%)$ & 0.04 \\
\hline Thoracic or respiratory diseases & $253(53.7 \%)$ & $90(66.7 \%)$ & 0.007 & $193(24.6 \%)$ & $12(33.3 \%)$ & 0.24 \\
\hline Renal or metabolic disease & $48(10.2 \%)$ & $13(9.6 \%)$ & 0.85 & $51(6.5 \%)$ & $3(8.3 \%)$ & 0.67 \\
\hline Gastrointestinal tract diseases & $56(11.9 \%)$ & $12(8.9 \%)$ & 0.33 & $102(13 \%)$ & $6(16.7 \%)$ & 0.53 \\
\hline Other & $21(4.5 \%)$ & $4(3 \%)$ & 0.44 & $15(1.9 \%)$ & $2(5.6 \%)$ & 0.13 \\
\hline Length of stay in ICU & $8(5,14)$ & $9(5,15)$ & 0.74 & $5(4,7)$ & $5(4,9)$ & 0.11 \\
\hline \multicolumn{7}{|l|}{ NSAIDs } \\
\hline \multirow{2}{*}{$\begin{array}{l}\text { Number of patients n (\%) } \\
\text { (Un adjusted odds ratio (95\% CI)) }\end{array}$} & $19(4 \%)$ & $12(8.9 \%)$ & 0.02 & $98(12.5 \%)$ & $1(2.8 \%)$ & 0.08 \\
\hline & \multicolumn{2}{|c|}{$(2.32(1.10,4.91))$} & \multicolumn{4}{|c|}{$(0.20(0.03,1.47))$} \\
\hline Delta body temperature* $\left({ }^{\circ} \mathrm{C}, \mathrm{IQR}\right)$ & $-0.4(-0.9,-0.1)$ & $-0.1(-0.6,0.0)$ & 0.08 & $-0.4(-0.7,0)$ & $0.0(0.0,0.0)$ & 0.30 \\
\hline \multicolumn{7}{|l|}{ Acetaminophen $\mathrm{n}(\%)$} \\
\hline \multirow[t]{2}{*}{$\begin{array}{l}\text { Number of patients } n(\%) \\
\text { (Un adjusted odds ratio (95\%Cl)) }\end{array}$} & 75 (15.9\%) & $41(30.4 \%)$ & 0.002 & $31(4 \%)$ & $1(2.8 \%)$ & 0.72 \\
\hline & \multicolumn{2}{|c|}{$(2.30(1.48,3.58))$} & \multicolumn{4}{|c|}{$(0.69(0.09,5.23))$} \\
\hline Delta body temperature $\left({ }^{\circ} \mathrm{C}, \mathrm{IQR}\right)$ & $-0.4(-1.1,-0.1)$ & $-0.4(-0.9,-0.2)$ & 0.94 & $-0.3(-0.7,0.0)$ & $-0.9(-0.9,-0.9)$ & 0.28 \\
\hline \multicolumn{7}{|l|}{ Cooling n (\%) } \\
\hline \multirow[t]{2}{*}{$\begin{array}{l}\text { Number of patients } \mathrm{n}(\%) \\
\text { (Unadjusted odds ratio }(95 \% \mathrm{Cl}) \text { ) }\end{array}$} & $223(47.3 \%)$ & $64(47.4 \%)$ & 0.99 & $366(46.7 \%)$ & $18(50 \%)$ & 0.74 \\
\hline & \multicolumn{2}{|c|}{$(1.00(0.68,1.46))$} & \multicolumn{4}{|c|}{$(1.14(0.58,2.22))$} \\
\hline Delta body temperature* $\left({ }^{\circ} \mathrm{C}, \mathrm{IQR}\right)$ & $-0.2(-0.4,0)$ & $-0.2(-0.5,0)$ & 0.55 & $-0.1(-0.3,0)$ & $-0.1(-0.4,0)$ & 0.16 \\
\hline
\end{tabular}

APACHE, Acute Physiology and Chronic Health Evaluation; Cl, confidential interval; IQR, 25\%, 75\% interquartile; NSAIDs, non-steroid anti-inflammatory drugs

*, Delta body temperature from application of antipyretic to next temperature monitoring

Table 4 Multivariate logistic analysis for 28-day mortality

\begin{tabular}{|c|c|c|c|c|}
\hline & \multicolumn{2}{|c|}{$\begin{array}{l}\text { Patients with sepsis } \\
\qquad(N=606)\end{array}$} & \multicolumn{2}{|c|}{$\begin{array}{l}\text { Patients without sepsis } \\
\qquad(N=819)\end{array}$} \\
\hline & $\begin{array}{c}\text { Adjusted odds ratio } \\
(95 \% \mathrm{Cl})\end{array}$ & $P$-value & $\begin{array}{c}\text { Adjusted odds ratio } \\
(95 \% \mathrm{Cl})\end{array}$ & $P$-value \\
\hline Age (y.o., IQR) & $1.01(0.99,1.02)$ & 0.32 & $1.01(0.98,1.04)$ & 0.39 \\
\hline APACHE (IQR) & $1.09(1.05,1.12)$ & $<0.001$ & $1.19(1.12,1.27)$ & $<0.001$ \\
\hline Postoperative admission n (\%) & $0.81(0.36,1.85)$ & 0.62 & $0.56(0.24,1.29)$ & 0.17 \\
\hline Mechanical ventilation requirement $\mathrm{n}(\%)$ & $1.72(1.01,2.94)$ & 0.045 & $3.85(1.40,10.6)$ & 0.01 \\
\hline Cardiac or vascular diseases & $0.87(0.43,1.76)$ & 0.70 & $1.03(0.38,2.75)$ & 0.96 \\
\hline Thoracic or respiratory diseases & $1.71(0.99,2.94)$ & 0.053 & $1.87(0.70,4.97)$ & 0.21 \\
\hline \multicolumn{5}{|l|}{ Max. body temp. during ICU stay } \\
\hline $37.5^{\circ} \mathrm{C}$ to $38.4^{\circ} \mathrm{C}$ (vs. $36.5^{\circ} \mathrm{C}$ to $37.4^{\circ} \mathrm{C}$ ) & $0.45(0.24,0.85)$ & 0.014 & $1.61(0.56,4.68)$ & 0.38 \\
\hline $38.5^{\circ} \mathrm{C}$ to $39.4^{\circ} \mathrm{C}$ (vs. $36.5^{\circ} \mathrm{C}$ to $37.4^{\circ} \mathrm{C}$ ) & $0.52(0.24,1.1)$ & 0.09 & $3.34(0.88,12.69)$ & 0.08 \\
\hline$\geq 39.5^{\circ} \mathrm{C}$ (vs. $36.5^{\circ} \mathrm{C}-37.4^{\circ} \mathrm{C}$ ) & $0.47(0.19,1.18)$ & 0.11 & $8.14(1.67,39.59)$ & 0.01 \\
\hline NSAIDs & $2.61(1.11,6.11)$ & 0.028 & $0.22(0.03,1.74)$ & 0.15 \\
\hline Acetaminophen & $2.05(1.19,3.55)$ & 0.01 & $0.58(0.06,5.26)$ & 0.63 \\
\hline Cooling & $1.2(0.70,2.05)$ & 0.50 & $0.71(0.30,1.69)$ & 0.44 \\
\hline
\end{tabular}

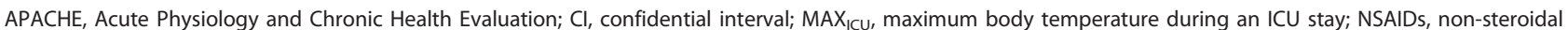
anti-inflammatory drugs

Subgroup with $\mathrm{MAX}_{\mathrm{ICU}}<36.5^{\circ} \mathrm{C}$ was excluded from this analysis because only three patients with sepsis and none without fell within this temperature range. 
Table 5 Multivariate logistic analysis for 28-day mortality in patients with lowest body temperature $>35^{\circ} \mathrm{C}$

\begin{tabular}{|c|c|c|c|c|}
\hline & \multicolumn{2}{|c|}{$\begin{array}{l}\text { Patients with sepsis } \\
\qquad(N=507)\end{array}$} & \multicolumn{2}{|c|}{$\begin{array}{l}\text { Patients without sepsis } \\
\qquad(N=715)\end{array}$} \\
\hline & $\begin{array}{c}\text { Adjusted odds ratio } \\
(95 \% \mathrm{Cl})\end{array}$ & $P$-value & $\begin{array}{c}\text { Adjusted odds ratio } \\
(95 \% \mathrm{Cl})\end{array}$ & $P$-value \\
\hline Age (y.o., IQR) & $1.02(1.00,1.03)$ & 0.08 & $1.01(0.98,1.05)$ & 0.52 \\
\hline APACHE (IQR) & $1.07(1.03,1.11)$ & $<0.001$ & $1.20(1.11,1.30)$ & $<0.001$ \\
\hline Postoperative admission n (\%) & $0.79(0.32,1.91)$ & 0.59 & $0.57(0.21,1.52)$ & 0.26 \\
\hline Mechanical ventilation requirement $\mathrm{n}(\%)$ & $1.76(0.98,3.14)$ & 0.06 & $3.49(1.14,10.7)$ & 0.03 \\
\hline Cardiac or vascular diseases & $0.85(0.39,1.82)$ & 0.67 & $0.73(0.24,2.21)$ & 0.57 \\
\hline Thoracic or respiratory diseases & $1.23(0.66,2.28)$ & 0.51 & $1.24(0.40,3.78)$ & 0.71 \\
\hline \multicolumn{5}{|l|}{$\operatorname{MAX}_{\mathrm{ICU}}$} \\
\hline $37.5^{\circ} \mathrm{C}$ to $38.4^{\circ} \mathrm{C}$ (vs. $36.5^{\circ} \mathrm{C}$ to $37.4^{\circ} \mathrm{C}$ ) & $0.42(0.20,0.88)$ & 0.02 & $3.18(0.78,12.9)$ & 0.11 \\
\hline $38.5^{\circ} \mathrm{C}$ to $39.4^{\circ} \mathrm{C}$ (vs. $36.5^{\circ} \mathrm{C}$ to $37.4^{\circ} \mathrm{C}$ ) & $0.60(0.25,1.43)$ & 0.25 & $7.49(1.47,38.1)$ & 0.02 \\
\hline$\geq 39.5^{\circ} \mathrm{C}$ (vs. $36.5^{\circ} \mathrm{C}$ to $37.4^{\circ} \mathrm{C}$ ) & $0.59(0.21,1.68)$ & 0.32 & $11.7(1.58,87.0)$ & 0.02 \\
\hline NSAIDs & $2.48(1.02,6.01)$ & 0.04 & $0.26(0.032,2.19)$ & 0.22 \\
\hline Acetaminophen & $1.95(1.06,3.57)$ & 0.03 & $0.61(0.23,1.61)$ & 0.32 \\
\hline Cooling & $1.23(0.69,2.21)$ & 0.47 & $1.26(0.14,11.0)$ & 0.84 \\
\hline
\end{tabular}

APACHE, Acute Physiology and Chronic Health Evaluation; Cl, confidential interval; MAX anti-inflammatory drugs

$<35.0^{\circ} \mathrm{C}$.), we performed further multivariate analysis and found a similar association of the use of pharmacological antipyretic with mortality. Fourth, any combination of the above factors might also apply.

There is limited information on the effect of antipyretics on patient outcomes and there are no recommendations for antipyretic treatments for febrile patients with or without infectious diseases [2,4]. One study of trauma patients was abandoned early with the $82^{\text {nd }}$ patient on instruction of a safety monitoring board. This study reported the trend toward increased risk of infection and death in patients when acetaminophen and physical cooling were aggressively used [30]. Additionally, two studies reported that short-term therapy with ibuprofen in patients with sepsis did not influence mortality [31,32]. To our knowledge, this study is the first multicenter examination of the epidemiology and outcome associations of antipyretic treatments [33]. While the clinical benefits and risk of antipyretic treatments can only be properly assessed in a randomized controlled trial; until such time, our findings do have some practical implications.

\section{Conclusions}

In conclusion, the association with mortality of fever and type of antipyretic treatment was different between patients with and without sepsis at admission to ICU. For non-septic patients, $\mathrm{MAX}_{\mathrm{ICU}} \geq 39.5^{\circ} \mathrm{C}$ was associated with 28-day mortality. Meanwhile, for septic patients, administration of NSAIDs and acetaminophen was independently associated with increased mortality. Since many ICU patients are or become febrile and antipyretic treatments are common, further studies now appear desirable to confirm or refute our observations.

\section{Key messages}

- The association of fever with mortality was different for patients with and without sepsis at admission to ICU.

- For patients without sepsis, $\mathrm{MAX}_{\mathrm{ICU}} \geq 39.5^{\circ} \mathrm{C}$ was associated with 28-day mortality.

- The association of pharmacological antipyretic treatments with mortality was different for patients with and without sepsis at admission of ICU.

- For patients without sepsis, administration of NSAIDs and acetaminophen was independently associated with increased mortality.

\section{Writing committee (contributions)}

Korea: Younsuck Koh, M.D. PhD (Division of Pulmonary and Critical Care Medicine, Department of Internal Medicine, Asan Medical Center, University of Ulsan College of Medicine, Seoul, republic of Korea); Jae Yeol Kim, M.D. (Department of Pulmonary and Critical Care Medicine, Chung-Ang University College of Medicine, Seoul, Republic of Korea); and Gee Young Suh, M.D. (Division of Pulmonary and Critical Care Medicine, Samsung Medical Center, Sungkyunkwan University School of Medicine, Seoul, Republic of Korea).

Japan: Masaji Nishimura, M.D. PhD (Department of Emergency and Critical Care Medicine, Tokushima University Hospital, Tokushima, Japan) and Moritoki Egi, M.D. (Department of Intensive Care, Okayama University Hospital, Okayama, Japan). 
ME and MN conceived the study. ME, MN, YK, JYK and GYS participated in the design of the study and coordinated patient enrollment and data collection for their respective countries. MN and JYK managed the data collection website for the respective countries. ME performed the statistical analyses. ME, MN, YK, JYK and GYS participated in data interpretation and drafted the manuscript. All authors read and approved the final manuscript.

\section{Additional material}

Additional file 1: Maximum body temperature during ICU stay and 28-day mortality of patients with and without sign of infection.

\section{Abbreviations}

APACHE: Acute Physiology and Chronic Health Evaluation; ICU: intensive care unit; $M A X_{I C U}$ : maximum body temperature during ICU stay; NSAIDs: nonsteroidal anti-inflammatory drugs; STROBE: Strengthening the Reporting of Observational Studies in Epidemiology.

\section{Acknowledgements}

The Korean Society of Critical Care Medicine and the Japanese Society of Intensive Care Medicine supported the travel expense for research committee members to JAKOICS meetings.

\section{Author details}

${ }^{1}$ Department of Anesthesiology, St. Paul's Hospital, Catholic University of Korea, Seoul, Republic of Korea. ${ }^{2}$ Department of Emergency and Critical Care Medicine, Tokushima University Hospital, Tokushima, Japan. ${ }^{3}$ Division of Pulmonary and Critical Care Medicine, Samsung Medical Center, Sungkyunkwan University School of Medicine, Seoul, Republic of Korea. ${ }^{4}$ Department of Pulmonary and Critical Care Medicine, Chung-Ang University College of Medicine, Seoul, Republic of Korea. ${ }^{5}$ Department of Anesthesiology and Pain Medicine, Pusan National University School of Medicine, Busan, Republic of Korea. 'School of Media, Seoul Women's University, Seoul, Republic of Korea. ${ }^{7}$ Department of Anesthesiology and Intensive Care Medicine, Hiroshima City Hospital, Hiroshima, Japan. ${ }^{8}$ Division of Intensive and Coronary Care Unit, Nippon Medical School Hospital, Tokyo, Japan. ${ }^{9}$ Tonami General Hospital, Toyama, Japan. ${ }^{10}$ Intensive Care Division, Ehime University Hospital, Ehime, Japan. ${ }^{11}$ Emergency \& Critical Care Medicine, Akita University Graduate School of Medicine, Akita, Japan. ${ }^{12}$ Department of Intensive Care, Okayama University Hospital, Okayama, Japan. ${ }^{13}$ Department of Internal Medicine, Misato Kenwa Hospital, Saitama, Japan. ${ }^{14}$ Intensive Care Unit, Department of Anesthesiology, Teine Keijinkai Hospital, Sapporo, Japan. ${ }^{15}$ Department of Anesthesiology, Kyoto Prefectural University of Medicine, Kyoto, Japan. ${ }^{16}$ Department of Anesthesiology and Pain Medicine, Seoul National University Hospital, Seoul, Republic of Korea. ${ }^{17}$ Anesthesiology and Critical Cate Medicine, Konkuk University Hospital, Seoul, Republic of Korea. ${ }^{18}$ Department of Anesthesiology and Critical Care Medicine, Saitama Medical Center, Jichi Medical University, Saitama, Japan. ${ }^{19}$ Division of Intensive Care Medicine, Kagoshima University Hospital, Kagoshima, Japan. ${ }^{20}$ Advanced Medical Emergency and Critical Care Center, Yamaguchi University Hospital, Yamaguchi, Japan. ${ }^{21}$ Department of Anesthesiology and Pain Medicine, Chungnam National University Hospital, Daejeon, Republic of Korea. ${ }^{22}$ Department of Emergency and Critical Care Medicine, St. Marianna University, Kanagawa, Japan. ${ }^{23}$ Department of Anesthesiology and Pain Medicine, Anesthesia and Pain Research Institute, Severance Hospital, Yonsei University College of Medicine, Seoul, Republic of Korea. ${ }^{24}$ Department of Anesthesiology and Pain Medicine, Incheon St Mary's Hospital, Catholic University of Korea, Medical College, Incheon, Republic of Korea. ${ }^{25}$ Innovation of New Biomedical Engineering Center, Tohoku University, Sendai, Japan. ${ }^{26}$ Department of Anesthesiology and Critical Care, Kamagaya General Hospital, Kamagaya, Japan. ${ }^{27}$ Division of Pulmonary and Critical Care Medicine, Department of Internal Medicine,
Asan Medical Center, University of Ulsan College of Medicine, Seoul, republic of Korea.

\section{Competing interests}

All principal investigators have no financial competing interests to disclose. There are no conflicts of interest to disclose related to this investigation.

Received: 14 October 2011 Revised: 21 February 2012

Accepted: 28 February 2012 Published: 28 February 2012

\section{References}

1. Laupland KB, Shahpori R, Kirkpatrick AW, Ross T, Gregson DB, Stelfox HT: Occurrence and outcome of fever in critically ill adults. Crit Care Med 2008, 36:1531-1535.

2. O'Grady NP, Barie PS, Bartlett JG, Bleck T, Carroll K, Kalil AC, Linden P, Maki DG, Nierman D, Pasculle W, Masur H, American College of Critical Care Medicine, Infectious Diseases Society of America: Guidelines for evaluation of new fever in critically ill adult patients: 2008 update from the American College of Critical Care Medicine and the Infectious Diseases Society of America. Crit Care Med 2008, 36:1330-1349.

3. Hawksworth JS, Leeser D, Jindal RM, Falta E, Tadaki D, Elster EA: New directions for induction immunosuppression strategy in solid organ transplantation. Am J Surg 2009, 197:515-524.

4. Dellinger RP, Levy MM, Carlet JM, Bion J, Parker MM, Jaeschke R, Reinhart K, Angus DC, Brun-Buisson C, Beale R, Calandra T, Dhainaut JF, Gerlach H, Harvey M, Marini JJ, Marshall J, Ranieri M, Ramsay G, Sevransky J, Thompson BT, Townsend S, Vender JS, Zimmerman JL, Vincent JL, International Surviving Sepsis Campaign Guidelines Committee, American Association of Critical-Care Nurses, American College of Chest Physicians, American College of Emergency Physicians, Canadian Critical Care Society, European Society of Clinical Microbiology and Infectious Diseases, European Society of Intensive Care Medicine, European Respiratory Society, International Sepsis Forum, Japanese Association for Acute Medicine, Japanese Society of Intensive Care Medicine, Society of Critical Care Medicine, Society of Hospital Medicine, Surgical Infection Society, World Federation of Societies of Intensive and Critical Care Medicine: Surviving Sepsis Campaign: international guidelines for management of severe sepsis and septic shock: 2008. Crit Care Med 2008, 36:296-327, Erratum in: Crit Care Med 2008, 36:1394-1396..

5. Manthous CA, Hall JB, Olson D, Singh M, Chatila W, Pohlman A, Kushner R, Schmidt GA, Wood LD: Effect of cooling on oxygen consumption in febrile critically ill patients. Am J Respir Crit Care Med 1995, 151:10-14.

6. Mild therapeutic hypothermia to improve the neurologic outcome after cardiac arrest. N Engl J Med 2002, 346:549-556.

7. Bernard SA, Gray TW, Buist MD, Jones BM, Silvester W, Gutteridge G, Smith K: Treatment of comatose survivors of out-of-hospital cardiac arrest with induced hypothermia. N Engl J Med 2002, 346:557-563.

8. Axelrod P: External cooling in the management of fever. Clin Infect Dis 2000, 31(Suppl 5):S224-229.

9. Fumagalli R, Bellani G, Perri A: Which drugs for the control of fever in critical patients. Curr Drug Targets 2009, 10:881-886.

10. Young P, Saxena M, Eastwood GM, Bellomo R, Beasley R: Fever and fever management among intensive care patients with known or suspected infection: a multicentre prospective cohort study. Crit Care Resusc 2011, 13:97-102.

11. Ryan AJ, Flanagan SW, Moseley PL, Gisolfi CV: Acute heat stress protects rats against endotoxin shock. J Appl Physiol 1992, 73:1517-1522.

12. Villar J, Ribeiro SP, Mullen JB, Kuliszewski M, Post M, Slutsky AS: Induction of the heat shock response reduces mortality rate and organ damage in a sepsis-induced acute lung injury model. Crit Care Med 1994, 22:914-921.

13. Kluger MJ, Kozak W, Conn CA, Leon LR, Soszynski D: The adaptive value of fever. Infect Dis Clin North Am 1996, 10:1-20.

14. Eyers $S$, Weatherall $M$, Shirtcliffe $P$, Perrin $K$, Beasley R: The effect on mortality of antipyretics in the treatment of influenza infection: systematic review and meta-analysis. J R Soc Med 2010, 103:403-411.

15. Brandts $\mathrm{CH}$, Ndjavé $M$, Graninger W, Kremsner PG: Effect of paracetamol on parasite clearance time in Plasmodium falciparum malaria. Lancet 1997, 350:704-709.

16. Muckart DJ, Bhagwanjee S: American College of Chest Physicians/Society of Critical Care Medicine Consensus Conference definitions of the 
systemic inflammatory response syndrome and allied disorders in relation to critically injured patients. Crit Care Med 1997, 25:1789-1795.

17. Bone RC, Balk RA, Cerra FB, Dellinger RP, Fein AM, Knaus WA, Schein RM, Sibbald WJ: Definitions for sepsis and organ failure and guidelines for the use of innovative therapies in sepsis. The ACCP/SCCM Consensus Conference Committee. American College of Chest Physicians/Society of Critical Care Medicine. 1992. Chest 2009, $136(5$ Suppl):e28

18. Knaus WA, Draper EA, Wagner DP, Zimmerman JE: APACHE II: a severity of disease classification system. Crit Care Med 1985, 13:818-829.

19. Laupland KB, Zahar JR, Adrie C, Schwebel C, Goldgran-Toledano D, Azoulay E, Garrouste-Orgeas M, Cohen Y, Jamali S, Souweine B, Darmon M, Timsit JF: Determinants of temperature abnormalities and influence on outcome of critical illness. Crit Care Med 2012, 40:145-151

20. von Elm E, Altman DG, Egger M, Pocock SJ, Gotzsche PC, Vandenbroucke JP: The Strengthening the Reporting of Observational Studies in Epidemiology (STROBE) statement: guidelines for reporting observational studies. Lancet 2007, 370:1453-1457.

21. Fulbrook P: Core temperature measurement: a comparison of rectal, axillary and pulmonary artery blood temperature. Intensive Crit Care Nurs 1993, 9:217-225.

22. Togawa T: Body temperature measurement. Clin Phys Physiol Meas 1985, 6:83-108.

23. Azzimondi G, Bassein L, Nonino F, Fiorani L, Vignatelli L, Re G D'Alessandro R: Fever in acute stroke worsens prognosis. A prospective study. Stroke 1995, 26:2040-2043.

24. Rossi S, Zanier ER, Mauri I, Columbo A, Stocchetti N: Brain temperature, body core temperature, and intracranial pressure in acute cerebral damage. J Neurol Neurosurg Psychiatry 2001, 71:448-454.

25. Dellinger RP, Levy MM, Carlet JM, Bion J, Parker MM, Jaeschke R, Reinhart K, Angus DC, Brun-Buisson C, Beale R, Calandra T, Dhainaut JF, Gerlach H, Harvey M, Marini JJ, Marshall J, Ranieri M, Ramsay G, Sevransky J, Thompson BT, Townsend S, Vender JS, Zimmerman JL, Vincent JL: Surviving Sepsis Campaign: international guidelines for management of severe sepsis and septic shock: 2008. Intensive Care Med 2008, 34:17-60, Erratum in: Intensive Care Med 2008, 34:783-785.

26. Pittet D, Thievent B, Wenzel RP, Li N, Auckenthaler R, Suter PM: Bedside prediction of mortality from bacteremic sepsis. A dynamic analysis of ICU patients. Am J Respir Crit Care Med 1996, 153:684-693.

27. Leroy O, Gangneux JP, Montravers P, Mira JP, Gouin F, Sollet JP, Carlet J, Reynes J, Rosenheim M, Regnier B, Lortholary O, AmarCand Study Group: Epidemiology, management, and risk factors for death of invasive Candida infections in critical care: a multicenter, prospective, observational study in France (2005-2006). Crit Care Med 2009, 37:1612-1618.

28. Hersch M, Raveh D, Izbicki G: Effect of intravenous propacetamol on blood pressure in febrile critically ill patients. Pharmacotherapy 2008 28:1205-1210.

29. Gozzoli V, Treggiari MM, Kleger GR, Roux-Lombard P, Fathi M, Pichard C, Romand JA: Randomized trial of the effect of antipyresis by metamizol, propacetamol or external cooling on metabolism, hemodynamics and inflammatory response. Intensive Care Med 2004, 30:401-407.

30. Schulman Cl, Namias N, Doherty J, Manning RJ, Li P, Alhaddad A, Lasko D, Amortegui J, Dy CJ, Dlugasch L, Baracco G, Cohn SM: The effect of antipyretic therapy upon outcomes in critically ill patients: a randomized, prospective study. Surg Infect (Larchmt) 2005, 6:369-375, Erratum in: Surg Infect (Larchmt) 2010, 11:495. Li, Pam (corrected to Li Pamela); Alhaddad, Ahmed (corrected to Elhaddad, Ahmed).

31. Bernard GR, Wheeler AP, Russell JA, Schein R, Summer WR, Steinberg KP, Fulkerson WJ, Wright PE, Christman BW, Dupont WD, Higgins SB, Swindell BB: The effects of ibuprofen on the physiology and survival of patients with sepsis. The Ibuprofen in Sepsis Study Group. N Engl J Med 1997, 336:912-918

32. Haupt MT, Jastremski MS, Clemmer TP, Metz CA, Goris GB: Effect of ibuprofen in patients with severe sepsis: a randomized, double-blind, multicenter study. The Ibuprofen Study Group. Crit Care Med 1991. 19:1339-1347.

33. Egi M, Morita K: Fever in non-neurological critically ill patients: a systematic review of observational studies. J Crit Care 2012.

\section{doi:10.1186/cc11211}

Cite this article as: Egi et al:: Association of body temperature and antipyretic treatments with mortality of critically ill patients with and without sepsis: multi-centered prospective observational study. Critical Care 2012 16:R33.

\section{Submit your next manuscript to BioMed Central and take full advantage of:}

- Convenient online submission

- Thorough peer review

- No space constraints or color figure charges

- Immediate publication on acceptance

- Inclusion in PubMed, CAS, Scopus and Google Scholar

- Research which is freely available for redistribution 